\title{
Secondary Prevention Recommendation Attainment with Cardiac Rehabilitation: Is there a Gender Disparity?
}

\author{
Karam I. Turk-Adawi, $\mathrm{PhD}^{\mathrm{a}, \mathrm{b}}$ \\ Neil B. Oldridge, $\mathrm{PhD}^{\mathrm{c}}$ \\ Mark J. Vitcenda, MS ${ }^{\mathrm{d}}$ \\ Sergey S. Tarima, $\mathrm{PhD}^{\mathrm{e}}$ \\ Sherry L. Grace, $\mathrm{PhD}^{\mathrm{f}, \mathrm{g}}$
}

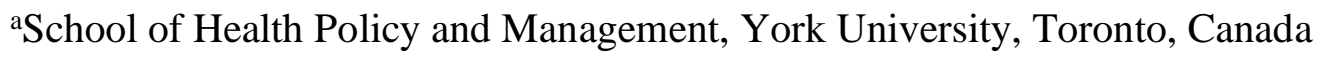

${ }^{\text {b}}$ The Heller School for Social Policy and Management, Brandeis University, Boston, USA

${ }^{\mathrm{c} C o l l e g e}$ of Health Sciences, University of Wisconsin-Milwaukee, Milwaukee, Wisconsin, USA

${ }^{\mathrm{d}}$ University of Wisconsin Hospital and Clinics, Madison, Wisconsin, USA

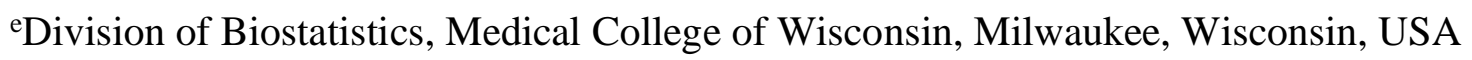

${ }^{\mathrm{f} F a c u l t y}$ of Health, York University, Toronto, Canada

'Toronto Rehabilitation Institute, University Health Network, Toronto, Canada

Corresponding author:

Karam Turk-Adawi

School of Health Policy and Management, York University, 4700 Keele Street

Toronto, Canada

Phone: 1-647-766-7711, Fax: 1-734-274-8899

Karamturk2000@yahoo.com

Source of fund: None. 


\title{
Secondary Prevention Recommendation Attainment with Cardiac Rehabilitation: Is there a Gender Disparity?
}

\begin{abstract}
Background: Achievement of secondary prevention guideline recommendations (i.e., goals) with cardiac rehabilitation (CR) is not well documented, specifically for women. This study examined achievement of the American Heart Association/American College of Cardiology (AHA/ACC) goals pre- and post-CR by gender.
\end{abstract}

METHODS: Of 12,976 patients enrolled in the Wisconsin CR Outcomes Registry, 8,929 $(68.8 \%)$ completed CR and were included in the sample. Attainment of 15 AHA/ACC goals preand post-CR was examined, by extracting corresponding data points in the Registry, as entered by CR program staff. Gender differences in achievement of these goals post-CR were examined via generalized estimating equations technique.

RESULTS: Attainment of AHA/ACC goals pre-CR ranged from 15.3\% of patients (physical activity) to $98.1 \%$ (aspirin), and by $17.6 \%$ (physical activity) to $98.4 \%$ (diastolic blood pressure) by CR completion. Significant improvements were achieved in $8(53.3 \%)$ goals, ranging from $0.7 \%$ for body mass index to $50.8 \%$ for physical activity. Women were significantly less likely than men to achieve the following goals by CR completion: triglycerides (adjusted odds ratio [AOR], 0.54; 95\% confidence interval [CI]: 0.45-0.66), physical activity (AOR, 0.66; CI 0.590.74), and hemoglobin $\mathrm{A}_{1 \mathrm{c}}(\mathrm{AOR}, 0.50$; $\mathrm{CI}$ 0.32-0.78). Women were significantly more likely than men to achieve the high-density lipoprotein goal (AOR, 1.39; CI 1.05-1.86). There were no significant gender differences in goal achievement for blood pressure, total cholesterol, lowdensity lipoprotein, body mass index, smoking cessation, or medication usage. More than $94 \%$ of 
patients were taking 3 of 4 recommended secondary prevention medications both pre-and postprogram.

CONCLUSIONS: Men and women generally improved similarly in terms of AHA/ACC goal achievement. Quality improvement strategies need to focus on physical activity and blood glucose control in women. 


\section{INTRODUCTION}

Despite the decline in coronary heart disease (CHD) mortality over the past 2 decades in the developed world, CHD remains the leading cause of death in both men and women in the United States (Go et al., 2013). With such a high incidence and prevalence, CHD secondary prevention recommendations have been established by the American Heart Association and the American College of Cardiology (AHA/ACC) to promote longevity in patients with CHD (Smith et al., 2006; Smith et al., 2011). The recommendations concern lipids, blood pressure, adiposity, diabetes mellitus, physical activity and smoking cessation, as well as adherence to medications. Similar recommendations are forwarded for women (Mosca et al., 2011), and given there is some evidence suggesting women with CHD may have poorer short-term outcomes than men (Vaccarino, Krumholz, Yarzebski, Gore, \& Goldberg, 2001, Pancholy, Shantha, Patel, \& Cheskin, 2014), secondary prevention goal attainment may be even more crucial in this group.

Cardiac rehabilitation (CR) is a chronic disease management model structured around assessment and management of CHD risk factors for secondary prevention. The programs offer structured exercise training, patient education, and risk reduction (American Association of Cardiovascular and Pulmonary Rehabilitation, 2013). Accordingly, the American Association of Cardiovascular and Pulmonary Rehabilitation (AACVPR) forwarded CR performance measures, which are consistent with the AHA/ACC secondary prevention targets, in 2007 (Thomas et al., 2007). Indeed, meta-analyses have established that CR participation is associated with greater risk factor control, and subsequently lower mortality and morbidity (Clark, Hartling, Vandermeer, McAlister, 2005; Lawler, Filion, \& Eisenberg, 2011; Oldridge, 2012).

Recently however, findings from "Rehabilitation After Myocardial Infarction Trial" (RAMIT) (West, Jones, \& Henderson, 2012) one of the largest studies of CR in the real-world setting, were published from the United Kingdom, suggesting no benefit of CR on outcomes 
from mortality to lifestyle risk factors. These findings have been controversial, with suggestion that the dose of CR was insufficient (i.e., $~ 8$ sessions vs. 36 in the United States) (Doherty \& Lewin, 2012). Hence, there is a need to better understand what is being achieved with CR in the United States in a "real-world" sample. Moreover, given that fewer women gain access to CR than men (Samayoa et al., 2014), comparison of outcomes between men and women participating in CR programs is limited (O'Farrell, Murray, Huston, LeGrand, \& Adamo, 2000; Sanderson, Mirza, Fry, Allison, \& Bittner, 2007; Sarrafzadegan et al., 2008).

To the best of our knowledge, only one study (Vogel et al., 2005) has compared gender differences in achievement of secondary prevention goals recommended by national clinical guidelines, namely the National Cholesterol Education Program Adult Treatment Panel III Guidelines issued in 2001(Expert Panel on Detection, Evaluation and Treatment, 2001), among $\mathrm{CR}$ attendees. Only an abstract is available, reporting that $>30 \%$ of patients were not at the guideline-based goal for 6 of 9 recommendations upon CR completion, and significant gender differences existed in achievement of 7 of the 9 goals. Accordingly, the objectives of this study were to examine: (a) change in secondary prevention measures pre to post-CR, namely CHD risk factors, physical activity levels, and medication use; (b) achievement of AHA/ACC guidelinebased secondary prevention goals at CR completion (presented in Table 1); and (c) whether achievement of these AHA/ACC guidelines varied by patient gender, in a population-based sample.

\section{METHODS}

\section{Study design and data source}

Institutional review board approval for the study was obtained from Brandeis University. This was a retrospective cohort study, where data were extracted from the Wisconsin Cardiac 
Rehabilitation Outcomes Registry (WiCORE) (Wisconsin Cardiac Rehabilitation Outcomes Registry, 2014). Data were contributed to the Registry by 79 of an estimated 120 CR programs $(65.8 \%)$ in the state.

CR programs in Wisconsin generally offer 36 sessions. CR staff will titrate medications to achieve secondary prevention targets or communicate with patients' other healthcare providers to recommend evidence-based medication changes. Each CR program offered is based on the AHA/ACC guidelines for secondary prevention issued in 2006 (Smith et al., 2006).

Patient data were collected by CR staff at each program using the WiCORE web-based interface. To optimize accuracy of data entry, CR staff were provided with a manual of how to navigate the interface and given a data dictionary (see relevant excerpts in the supplementary file). Additionally, the WiCORE incorporates data validation rules for each field to decrease input errors (e.g., out of range values). The WiCORE database is compliant with Health Insurance Portability and Accountability Act and included only de-identified patient information that can be transmitted without prior agreements (Wisconsin Cardiac Rehabilitation Outcomes Registry, 2014).

\section{Participants}

CR programs in Wisconsin generally provide care to patients with CR indications recognized by national organizations (Leon et al., 2005) or patients with Centers for Medicare and Medicaid Services-reimbursed indications such as acute coronary syndrome, revascularization, stable heart failure and heart valve repair or replacement (Centers for Medicare \& Medicaid Services, 2015). From July 2008 (registry inception) to January 2010, 17,000 patients' referral requests were entered in the registry, of these 8,929 patients completed $\mathrm{CR}$ and comprised the sample of this study. Completion of CR was defined in WiCORE as one or more of the following: (a) the patient completed the number of prescribed sessions or 
prescribed duration; (b) the patient completed the maximal number of sessions or duration allowed by insurance coverage; or (c) the patient met the exercise and education goals before the typical 3 months or insurance coverage limit was reached (Wisconsin Society for Cardiovascular and Pulmonary Health and Rehabilitation, 2008). There were no exclusion criteria.

\section{Measures}

Sociodemographic and Clinical Characteristics

Data fields can be accessed at https://wicore.wisc.edu/DemographicsDemo.aspx. The WiCORE data set included gender, ethnicity, age, tobacco use (“current" smoker or having quit within the past 12 months; "former" smoker as having quit smoking more than 12 months prior to the assessment; or "never smoked"), AACVPR risk stratification (low, moderate, high, as defined in the AACVPR Guidelines (p. 63) (American Association of Cardiovascular \& Pulmonary Rehabilitation, 2004), documented history of depression (yes/ no), days to CR program start (days from hospital admission due to a cardiac event or time from a referral date for angina diagnosis to the first CR exercise session), CR indication (e.g., myocardial infarction, angina, coronary artery bypass surgery $[\mathrm{CABG}]$, percutaneous coronary intervention $[\mathrm{PCI}]$, heart failure, valvular repair/replacement), history of CHD (yes/ no), and comorbid conditions.

\section{Secondary Prevention Goals}

Attainment of the secondary prevention goals was operationalized based on the AHA/ACC guideline recommendations for patients with coronary and other vascular disease (Update 2006 was current through 2010; these were the current guidelines corresponding to the registry data presented herein) (Smith et al., 2006 Smith et al., 2011). Fifteen goals, which represents all of the AHA/ACC recommendations except influenza vaccination and aldosterone blockade (only applicable to select patients) (Smith et al., 2006 Smith et al., 2011), were 
examined (Table 1). Clinical measures corresponding to the intervention recommendations assessed both pre- and post-program were: body mass index (BMI), waist circumference, total cholesterol, low-density lipoprotein (LDL), high-density lipoprotein (HDL), triglycerides, systolic blood pressure, diastolic blood pressure, hemoglobin $\mathrm{A}_{1 \mathrm{C}}\left(\mathrm{Hb}_{1 \mathrm{C}}\right.$ for patients diagnosed with diabetes), and physical activity (i.e., minutes/week assessed via patient-report to CR staff member). Systolic and diastolic blood pressure targets were different for patients with diabetes or chronic kidney disease, and were hence examined separately. Medication use pre- and postprogram was also assessed (i.e., $\beta$-blockers, angiotensin converting enzyme-inhibitors or angiotensin receptor blockers [ACE-I/ARB], lipid-lowering agents, and aspirin). Patients with documented contraindications to these medications were captured in the registry and were excluded from the corresponding denominator. Changes in absolute values in cardiac risk factors (e.g., blood pressure, lipids, $\mathrm{HbA}_{1 \mathrm{c}}$ ), physical activity (minutes/week), and medication use (\%) were computed pre to post-program. Available clinically-important differences (CID) for goals were ascertained from the literature (Gould et al., 1998; Briel et al., 2009; Wen et al., 2011; Critchley \& Capewell, 2003), and used to establish whether the changes achieved were clinically significant. Goal attainment was expressed in dichotomous fashion as either yes or no postprogram.

\section{Statistical Analyses}

Summary statistics were used to describe pre-CR sociodemographic and clinical characteristics of the sample by CR completion status, to explore the generalizability of the sample, and by gender. Differences in these characteristics by completion status as well as by gennder were assessed by fitting generalized linear models via generalized estimating equations (GEE) procedure, which accounts for clustering of patients within programs. Thus, single predictor (completion status for the first model or gender or the second model was the only 
independent variable) via GEE with the LOGIT link function was specified to investigate the association with categorical characteristics and the identity link function was used for associations with continuous characteristics. The effect of the CR program was accounted for by the exchangeable correlation matrix in all our GEE models.

To test the first objective, changes in absolute values of secondary prevention measures from enrollment into a program to its completion were assessed in 2 steps. First, for each variable (for example, total cholesterol), we created the natural logarithm of the ratio of the value of a risk factor at completion divided by the baseline value of that factor. This transformation converted the pre- and post- intervention assessments into a single quantity addressing multiplicative change between pre-post values. Then, these composites [ln (value at completion /value at baseline)] were used as dependent variables in intercept-only GEE models, where the statistical significance of the pre-post multiplicative change was assessed.

To test the second objective, the rates of patients achieving the secondary prevention goals post-program were described. To examine the third objective of differences between men and women in achieving the AHA/ACC secondary prevention goals at CR completion, multiple regression analysis was conducted, via GEE, for each AHA/ACC goal (the dependent dichotomous variable) where gender (male, female) was the independent variable. Each model was adjusted for age, ethnicity, CR indication, comorbidities, history of depression (yes, no), smoking status (never, former, current), AACVPR-risk category (low, moderate, high), days to start the program, number of CR sessions attended, pre-program medication use, pre-program BMI, and pre-program physical activity. The models also adjusted for pre-program clinical measures including LDL, HDL, total cholesterol, triglycerides, and systolic and diastolic blood pressure. The LOGIT link function and the exchangeable working correlation matrix were 
specified in the GEE analyses. A p-value of $<.05$ was considered statistically significant. All statistical analyses were performed using SPSS 19.0 (IBM Corporation, 2012).

\section{RESULTS}

Of the 17,000 referred patients in the Registry, 12,976 (76.3\%) patients enrolled (defined as attending at least $1 \mathrm{CR}$ session), and 8,929 (52.5\%) completed CR and comprise the sample (Figure 1). There was no significant gender difference in CR enrollment (trend for more enrolment in men, $\mathrm{p}=.07)$. There was a significant difference in $\mathrm{CR}$ completion, with men completing more often than women $(\mathrm{p}=.001)$.

The sociodemographic and clinical characteristics of the sample of CR completers is shown in Table 2. As also shown, there were some significant differences in the characteristics of completers versus the non-completers. CR completers were more often of white ethnicity, older, non-smoking, had lower AACVPR risk, and were more likely to have CABG and valve disease but less likely to have PCI, angina, heart failure, and previous history of CHD than those who enrolled and did not complete the program. Completers also had fewer numbers of comorbidities, namely diabetes, arthritis, pulmonary disease, depression, back or other chronic pain, peripheral vascular disease, and renal disease, than non-completers.

Completers attended $22.2( \pm 9.2$; standard deviation; $61.7 \%)$ of the 36 sessions in a typical CR program in the United States (Medicare Interactive, 2015). Of the cohort, 1.7\%, 1.3\%, 0.8\% and $0.7 \%$ had contraindications to ACE-I/ARB, $\beta$-blockers, aspirin, and lipid-lowering agents, respectively.

Gender differences in the sociodemographic and clinical characteristics of the sample are presented in Table 3 . Women were significantly older, less likely to smoke, less likely to have 
CABG, more likely to have valvular disease and to have heart failure, and less likely to have previous coronary heart disease than men. Women were significantly more likely than men to have the following comorbid conditions: arthritis, gastro-intestinal diseases, renal disease, mental health problems (including depression), renal disease, and chronic pain.

\section{$\underline{\text { Secondary prevention outcomes }}$}

Table 4 compares absolute risk factor values and rates of medication use pre- and postprogram in men and women. Comparison is made both within groups (pre-post), as well as between groups for change by gender (see "change" column). Following participation in CR, both men and women showed statistically significant improvement in total cholesterol, triglycerides, LDL, diastolic blood pressure, physical activity, and smoking cessation; all patients with diabetes achieved significant reductions in $\mathrm{HbA}_{1 \mathrm{c}}$. Only women achieved significant reductions in systolic blood pressure. Use of ß-blockers, aspirin, and lipid medications was > $90 \%$ pre-CR, with about 2/3rds using ACE-I/ARBs, with little change over the duration of the CR program.

With regard to gender differences in goal change from pre to post-program, men achieved a significantly greater improvement in triglycerides and physical activity than women; women had a significant greater improvement in systolic blood pressure than men (Table 4). No other gender differences in change were observed. The magnitude of change was larger than the CID for women and men for LDL, while it was larger than CID only for men for total cholesterol. $\underline{\text { AHA/ACC goal achievement }}$

Table 5 describes the percentage of patients who were at the AHA/ACC goals pre- and post-program and the proportion of change in goal achievement with $\mathrm{CR}$. The proportions of patients in the overall cohort who had achieved AHA/ACC secondary prevention goals pre-CR ranged from $15.3 \%$ (physical activity) to $98.1 \%$ (aspirin), and from $17.6 \%$ (BMI) to $98.4 \%$ 
(diastolic blood pressure) post-CR. Rates of improvement in achieving goals for risk factors ranged from $0.7 \%$ (BMI) to $50.8 \%$ (physical activity) by CR completion. Notably, the lowest goal achieved by patients both pre- and post-program was BMI with $<20 \%$ of patients achieving this goal, whereas the highest goal achieved was use of secondary prevention medications (ßblocker, aspirin, and lipid-lowering agents) with $\geq 94 \%$ pre- and post-program. There was a significant increase in the proportion of patients who achieved goals for total cholesterol, LDL, triglycerides, systolic blood pressure, $\mathrm{HbA}_{1 \mathrm{c}}$, physical activity, and non-smoking at program completion. Both men and women had a significant increase in the achievement of waist circumference goals by CR completion.

Table 5 also shows gender differences in goal attainment pre- and post-CR. As shown, women were significantly less likely than men to achieve all the AHA/ACC secondary prevention goals prior to $\mathrm{CR}$ except for HDL, BMI and smoking cessation, which were more often met in women $(\mathrm{p}<.05)$. Specifically, women were less likely than men to achieve the following goals pre-CR program: total cholesterol $(\mathrm{p}<.05), \operatorname{LDL}(\mathrm{p}<.05)$, triglycerides $(\mathrm{p}<.05)$, and systolic blood pressure (both in patients with diabetes and without; $p<.05$ for each).

Gender differences in attainment of AHA/ACC goals by CR completion were tested through GEE after exclusion of patients who were at targets pre-program (Table 6). Compared to men, women were significantly less likely to attain triglycerides $<150 \mathrm{mg} / \mathrm{dl}$, physical activity $\geq 150$ minutes/week, and $\mathrm{HbA}_{1 \mathrm{C}}<7 \%$ (for patients with diabetes), while women were significantly more likely than men to attain HDL >40mg/dl.

\section{DISCUSSION}

This is the first study, to the best of our knowledge, to comprehensively examine rates of AHA/ACC secondary prevention goal attainment pre- and post-CR by gender. Substantial variation in rates of achievement of the AHA/ACC secondary prevention goals pre-CR was 
observed. By CR completion, rates of achieving AHA/ACC secondary prevention goals were still wide-ranging. If we set an $85 \%$ benchmark post-CR, improvements would still be required for both men and women in relation to LDL, HDL, triglycerides, BMI, waist circumference, systolic blood pressure for patients with diabetes or renal disease, HbAlc (for patients with diabetes), physical activity and ACEI/ARB use. Overall then, only 46.7\% (7/15) of recommendations were considered as met (i.e. $\geq 85 \%$ benchmark) by CR completion. Clearly, there is substantial room for improvement.

It was curious that a gender difference in CR enrolment was not observed in this cohort, although such a gender difference has been well-established (Samayoa et al., 2014). In the literature, lack of referral of women to CR by health professionals has been documented among the reasons of women's low enrollment (Scott, Ben-Or, Allen, 2002). The present study consisted of the population of patients who had been formally referred to one of the WiCOREparticipating $\mathrm{CR}$ programs, (i.e. a $\mathrm{CR}$ referral request received by $\mathrm{CR}$ staff who then contacted patients); this may partially explain the similarity in enrollment between men and women in our cohort. The significant gender difference in CR completion established in the literature was replicated in this study.

Compliance with 11 AHA/ACC cardiac performance measures was reported for outpatients with coronary artery disease in the PINNACLE study (Chan et al, 2010). While the targets were not exactly the same as herein, a similarly wide range of goal attainment was observed, from $13.3-94.0 \%$. Tobacco abstinence and diabetes screening were $71.2 \%$ and $13.3 \%$, respectively. We found higher rates of $85.5 \%$ for tobacco and $>50 \%$ of diabetic patients with $\mathrm{HbA}_{1 \mathrm{c}}$ assessed pre-program, with significant improvements observed for both by $\mathrm{CR}$ completion. If we applied the same $85 \%$ benchmark, only $36.7 \%$ (4/11) targets were met in this 
outpatient sample. Interestingly, PINNACLE showed only $18.1 \%$ of patients were referred to CR.

Almost all patients were taking 3 of the 4 recommended preventive medications, namely ß-Blockers, lipid-lowering therapy, and aspirin, both pre- and post-CR program. However, only 2/3rds of those without contraindication were on ACE-I or ARBs. High medication use was also observed in PINNACLE, including B-Blocker (86.4\%), anti-platelet therapy (84.9\%), LDLlowering therapy (84.3\%), with similarly lower use of ACE-I/ARB (72.4\%) (Chan et al, 2010). In this CR sample, even higher rates of medication use was observed, at $\geq 94 \%$ for the aforementioned medications. The exception in both samples was ACE-I/ARB use. This low ACE-I/ARB use rate persisted at CR program completion in our sample. A recent study of 85,017 Medicare beneficiaries similarly reported lower ACE-I/ARB use of 55\%, compared to 76\%, and 61\% for B-blockers, and statins, respectively (Lauffenburger, Robinson, Oramasionwu, \& Fang, 2014). A possible explanation could be that ACE-I/ARB is considered as second-line therapy in patients with stable coronary artery disease, as demonstrated by the PEACE trial (The PEACE Trial Investigators, 2004). However, reasons, both physician and patient-related, of low use of this preventive therapy warrant study.

The least-achieved AHA/ACC secondary prevention goal at CR completion was BMI, among all patients. The Clinical Outcomes Utilizing Revascularization and Aggressive Drug Evaluation (COURAGE) study similarly showed improvement across most coronary risk factors, but the poorest improvement was also observed for weight loss (Boden et al., 2007). A possible explanation is that with physical activity, patients gain muscle and thus weight. Waist circumference could be a better indicator for adiposity than BMI. In this cohort, indeed the proportion of men at waist circumference goal (<40inch) improved significantly from $37.3 \%$ to 
$43.1 \%$ from pre to post-program ( $\mathrm{p}<.05)$. With regard to women's goal ( $<35 \mathrm{inch})$, achievement similarly improved significantly from $28.2 \%$ to $31.8 \%$ ( $<<.05)$.

Clinical significance of changes observed with CR

The present study demonstrated that both men and women achieved significant improvements in secondary prevention measures by CR discharge, namely total cholesterol, $\mathrm{LDL}$, triglycerides, diastolic blood pressure, and $\mathrm{HbA}_{1 \mathrm{c}}$. Previous meta-analysis reported that a decrease of $10 \%$ in total cholesterol level is associated with significant decreases of $15 \%$ in the risk for CHD-related mortality and $11 \%$ in risk for all-cause mortality (Gould, Rossouw, Santanello, Heyse, Furberg, 1998). In our study, reduction in total cholesterol was of clinical significance for men, and almost for women, with a decrease of $10.3 \%$ and $9.3 \%$, respectively. Similarly, a reduction of $10 \mathrm{mg} / \mathrm{dl}$ in LDL in a meta-analysis was associated with significant relative risk reductions of $7.2 \%$ for CHD deaths, $7.1 \%$ for CHD events, and $4.4 \%$ for total deaths (Briel et al., 2009). Hence, the reduction in LDL observed with CR herein was of clinical significance in women $(15.5 \mathrm{mg} / \mathrm{dl})$ and men $(14.2 \mathrm{mg} / \mathrm{dl})$. Similarly, the $8.3 \%$ reduction observed in the proportion of patients smoking tobacco was clinically significant; a meta-analysis of 20 prospective cohort studies demonstrated that quitting smoking was associated with $36 \%$ reduction of death over a five-year period in patients with CHD (Critchley \& Capewell, 2004).With regard to other risk improvements, though there were significant reductions in triglyceride levels and in diastolic blood pressure, these changes would not be considered clinically meaningful (Grossman, 2011; Stauffer, Weisenfluh, \& Morrison, 2013).

Physical activity improved remarkably, with an increase of 119 and 130 minutes/week for women and men, respectively. This was the largest improvement among the AHA/ACC secondary prevention goals, and is commensurate with the aims of CR. This increase was clinically-significant; Wen and colleagues (2011) showed that exercising of 92 minutes per week 
(i.e., about 15 minutes a day) has been associated with a $14 \%$ reduced risk of all-cause mortality, and a 3-year longer life expectancy. Moreover, an additional 15 minutes of daily exercise beyond the minimum amount of 15 minutes a day was associated with a $4 \%$ further reduction in allcause mortality (Wen et al., 2011). In the present cohort, the average increases in physical activity observed may then may be associated with more mortality reduction than the aforementioned 14\% associated with 92 minutes/week. Despite the magnitude of improvement in physical activity goal, it must be conceded that the standard deviations were high. Moreover, the improvements were insufficient to meet an $85 \%$ benchmark, which is somewhat surprising given structured exercise is a core CR component (American Association of Cardiovascular and Pulmonary Rehabilitation, 2013).

Gender differences in attainment of AHA/ACC secondary prevention goals by CR completion

Even though women were older, with a higher comorbid health burden and less likely to attain most of the AHA/ACC secondary prevention goals pre-CR (Table 5), they were as likely as men to achieve significant improvements in CHD risk factors and most AHA/ACC secondary prevention goals by CR completion. Significant gender differences were observed in $28.6 \%$ of goals (4/14, excluding waist circumference due to different gender goals) by CR completion. Differences in changes in triglycerides, HbA1c and physical activity favouring men were observed, with the opposite for HDL. It is well-documented that women are less likely than men to commit a significant amount of time to physical activity (Heesch, Brown, \& Blanton, 2000; Im, Lee, Chee , \& Stuifbergen, 2011). As outlined above, only one study, a conference abstract, has compared gender differences in achievement of secondary prevention goals recommended by national clinical guidelines in CR. Our results are consistent with those of Vogel et al. (2005) who reported a lower proportion of women than men meeting the triglycerides and physical activity goals by CR completion, but they observed a higher proportion of women meeting HDL 
and BMI goals compared to men. With regard to the HDL goal, higher goal achievement compared to men could be attributed to the estrogen produced by women, which tends to raise HDL cholesterol (American Heart Association, 2014).

\section{Implications for Practice and/or Policy}

Women and men achieved most AHA/ACC secondary prevention goals through CR participation. Though women were less likely than men to achieve AHA/ACC secondary prevention goals pre-CR, they were as likely as men to achieve most of the AHA/ACC secondary prevention goals by CR completion. This suggests that CR can play an important role in reducing health disparities between men and women with CHD. Improvements were considered clinically significant for total cholesterol, LDL, physical activity, and smoking cessation. These findings highlight $\mathrm{CR}$ as an integral part of the continuum of care for cardiac patients, and that there is a continuing need to promote CR utilization by patients. Further, the state CR association should implement quality improvement initiatives to improve adiposity and diabetes control, and to promote greater physical activity on non-CR days, especially among women.

\section{Limitations}

This study is not without limitations, particularly in relation to measurement, generalizability and design. First, physical activity was assessed using a single item reported to a CR staff member. It is well known that patients often over-estimate the amount of physical activity they perform due to social desirability bias (Prince et al., 2008). This could have led to an over-estimation of the number of patients achieving the physical activity target; although, assuming that both men and women overestimate their activity levels equally, the significant 
gender difference is likely sound. Second, lipid tests were missing for many participants postprogram. Therefore, the findings related to lipids should be interpreted with caution. Third, medication use rates were very high. They were much higher than adherence rates reported in the literature. This could be due to the fact that physicians who refer their patients to CR practice and provide care in compliance with the clinical practice guidelines recommending CR referral and medication prescription, and that patients self-reporting adherence to prescribed medications to CR program staff may respond in a socially-desirable fashion. Therefore, the rates of medication use reported herein may be inflated.

Fourth, results are limited in generalizability to patients participating in CR programs that participate in WiCORE in the state of Wisconsin. While a majority of programs in the state participate in WiCORE, these programs may be of higher quality than programs that do not, and hence rates of AHA/ACC goal attainment might be higher than what would be observed in the non-participating programs. Moreover, while CR delivery across the United States is generally based on AACVPR guidelines, there could be differences in how CR is delivered in Wisconsin compared to other states and therefore caution is warranted in generalizing these findings to other states. Fifth, these findings are only generalizable to patients who completed CR. This is due to the differences observed between these patients and those who enrolled but did not complete the program. For example, completers were older, more often had CABG, had fewer comorbid conditions and were less likely to smoke than non-completers.

Sixth, some patients with a primary CR indication of valve disease or heart failure may not have had underlying CHD, and hence some of the goals may not have been relevant. For example, medications for patients with heart failure and valvular disease might be different from those for patients with CHD as they depend on the stage of the disease (Yancy et al., 2013; 
Nishimura et al., 2014). However, these indications were not as common as the CHD indications in the cohort and $74.6 \%$ of patients with heart failure and $38.6 \%$ of patients with valvular disease had a previous history of coronary heart disease. Seventh, because they were not assessed in the registry, consideration of factors that may have affected patient outcomes, such as income or visits to other healthcare providers, was not possible. The final limitation relates to design. These results should be interpreted with caution as there was no control group of patients who did not complete CR. Therefore, it cannot be ruled out that the changes in the outcomes observed could be due to some unmeasured factors.

\section{CONCLUSIONS}

CR participation improved achievement of most AHA/ACC secondary prevention goals in men and women, other than medications which were highly-utilized pre-program. Use of ACE-I/ARBs was notably lower than the other evidence-based medications. There were no benefits observed for BMI, however significant reductions in waist circumference were achieved. Improvements were considered clinically significant for total cholesterol, LDL, physical activity, and smoking cessation, and attainment of targets appeared to be more fulsome than what is observed in outpatient cardiac samples more broadly. However, CR programs could benefit from quality improvement activities for adiposity and diabetes control, and promoting greater physical activity among women specifically. 


\section{Acknowledgements}

We gratefully acknowledge the efforts of the many CR programs and their staff who participated in the WiCORE project.

\section{References}

American Association of Cardiovascular and Pulmonary Rehabilitation. (2004). Guidelines for cardiac rehabilitation and secondary prevention programs: Promoting health and preventing diease. (4 ${ }^{\text {th }}$ ed.).Champaign, IL: Human Kinetics Publishers, Inc.

American Association of Cardiovascular and Pulmonary Rehabilitation (2013). Guidelines for cardiac rehabilitation and secondary prevention programs: Promoting health and preventing diease.(5 $5^{\text {th }}$ ed.) Champaign, IL: Human Kinetics Publishers, Inc. 
American Heart Association. Women and cholesterol. Available:

http://www.heart.org/HEARTORG/Conditions/Cholesterol/UnderstandYourRiskforHigh Cholesterol/Women-and-Cholesterol_UCM_305565_Article.jsp\#. Accessed November $25,2015$.

Boden, W.E., O'Rourke, R.A., Teo, K.K., Hartigan, P.M., Maron, D.J., Kostuk, W.J., ... Weintraub, W,S. (2007). Optimal medical therapy with or without PCI for stable coronary disease. N Engl J Med, 356(15), 1503-16.

Briel, M., Ferreira-Gonzalez, I., You, J.J., Karanicolas, P.J., Akl, E.A., Wu, P., ... Guyatt, G.H. (2009). Association between change in high density lipoprotein cholesterol and cardiovascular disease morbidity and mortality: Systematic review and meta-regression analysis. BMJ, 338:b92. doi: http://dx.doi.org/10.1136/bmj.b92

Centers for Medicare \& Medicaid Services. Decision memo for cardiac rehabilitation (CR) programs - chronic heart failure (cag-00437n). Available: http://www.cms .gov/medicarecoverage-database/details/nca-decision-memo.aspx?NCAId=270. Accessed March 12, 2015.

Chan, P.S., Oetgen, W.J., Buchanan, D., Mitchell, K., Fiocchi, F.F., Tang, F., ... Spertus, J.A. (2010) Cardiac performance measure compliance in outpatients: The American College of Cardiology and National Cardiovascular Data Registry's PINNACLE (Practice Innovation And Clinical Excellence) program. J Am Coll Cardiol, 56(1), 8-14. doi: 10.1016/j.jacc.2010.03.043

Clark, A.M., Hartling, L., Vandermeer, B., \& McAlister, F.A. (2005). Meta-analysis: Secondary prevention programs for patients with coronary artery disease. Ann Intern Med, 143(9), 659-672. 
Critchley, J. \& Capewell, S. (2003). Smoking cessation for the secondary prevention of coronary heart disease. Cochrane Database Syst Rev, 4:CD003041.

Doherty, P., \& Lewin, R. (2012). The RAMIT trial, a pragmatic RCT of cardiac rehabilitation versus usual care: what does it tell us? Heart, 98(8), 605-606. doi: 10.1136/heartjnl-2012301728

Expert Panel on Detection, Evaluation, and Treatment of High Blood Cholesterol in Adults (2001). Executive summary of the third report of the National Cholesterol Education Program (NCEP) Expert Panel on Detection, Evaluation, And Treatment of High Blood Cholesterol in Adults (Adult Treatment Panel III). JAMA, 285(19), 2486-2497.

Go, A.S., Mozaffarian, D., Roger, V.L., Benjamin, E.J., Berry, J.D., Borden, W.B., ... Turner, M.B . (2013). Heart Disease and Stroke Statistics-2013 Update: A Report From the American Heart Association. Circulation, 127(1), e6-e245. doi:

10.1161/CIR.0b013e31828124ad

Gould, A.L., Rossouw, J.E., Santanello, N.C., Heyse, J.F., \& Furberg, C.D. (1998). Cholesterol reduction yields clinical benefit: Impact of statin trials. Circulation, 97(10), 946-952.

Grossman E. (2011). Blood pressure: The lower, the better: The con side. Diabetes Care, 34(Suppl 2), S308-S312.

Heesch, K.C., Brown, D.R., Blanton, C.J. (2000). Perceived barriers to exercise and stage of exercise adoption in older women of different racial/ethnic groups. Women Health, 30(4), $61-76$.

IBM Corporation.(2012). IBM SPSS Statistics for Windows, Version 21.0. Armonk, NY: IBM Corp.

Im, E-O., Lee, B., Chee, W., \& Stuifbergen, A. (2011). Attitudes toward physical activity of white midlife women. J Obstet Gynecol Neonatal Nurs, 40(3), 312-21. 
Lauffenburger, J.C., Robinson, J.G., Oramasionwu, C., \& Fang, G. (2014). Racial/Ethnic and gender gaps in the use of and adherence to evidence-based preventive therapies among elderly Medicare Part D beneficiaries after acute myocardial infarction. Circulation, $129(7), 754-63$.

Lawler, P., Filion, K., \& Eisenberg, M. (2011). Efficacy of exercise-based cardiac rehabilitation post-myocardial infarction: A systematic review and meta-analysis of randomized controlled trials. Am Heart J, 162(4), 571-584. doi: 10.1016/j.ahj.2011.07.017

Leon, A.S., Franklin, B.A., Costa, F., Balady, G.J., Berra, K.A., \& Stewart, K.J., ...Lauer, M.S. (2005). Cardiac rehabilitation and secondary prevention of coronary heart disease: An American Heart Association scientific statement from the Council on Clinical Cardiology (Subcommittee on Exercise, Cardiac Rehabilitation, and Prevention) and the Council on Nutrition, Physical Activity, and Metabolism (Subcommittee on Physical Activity), in collaboration with the American Association of Cardiovascular and Pulmonary Rehabilitation. Circulation, 111(3), 369-376

Medicare Interactive. Medicare coverage of cardiac rehabilitation. Available: http://www.medicareinteractive.org/page2.php?topic=counselor\&page=script\&script_id=354. Accessed January 9, 2015.

Mosca, L., Benjamin, E.J., Berra, K., Bezanson, J.L., Dolor, R.J., Lloyd-Jones, D.M.,... Wenger. N.K. (2011). Effectiveness-based guidelines for the prevention of cardiovascular disease in women--2011 update: A guideline from the American Heart Association. Circulation, 123(11), 1243-62. doi: 10.1161/CIR.0b013e31820faaf8

Nishimura, R.A., Otto, C.M., Bonow, R.O., Carabello, B.A., Erwin II I, J. P., Guyton, R. A., ... Thomas, J. (2014). 2014 AHA/ACC Guideline for the Management of Patients With Valvular Heart DiseaseA Report of the American College of Cardiology/American Heart 
Association Task Force on Practice Guidelines. J Am Coll Cardiol, 63(22), e57-e185. doi: 10.1161/CIR.0000000000000029

O'Farrell, P., Murray, J., Huston, P., LeGrand, C., \& Adamo, K. (2000). Sex differences in cardiac rehabilitation. Can J Cardiol,16(3), 319-25.

Oldridge, N. (2012). Exercise-based cardiac rehabilitation in patients with coronary heart disease: meta-analysis outcomes revisited. Future Cardiol, 8(5), 729-751.

Pancholy, S., Shantha, G., Patel, T., \& Cheskin, L. J. (2014). Sex differences in short-term and long-term all-cause mortality among patients with st-segment elevation myocardial infarction treated by primary percutaneous intervention: A meta-analysis. JAMA Intern Med, 174(11), 1822-1830. doi: 10.1001/jamainternmed.2014.4762.

Prince, S.A., Adamo, K.B., Hamel, M.E., Hardt, J., Connor, G., Tremblay, M. (2008). A comparison of direct versus self-report measures for assessing physical activity in adults: A systematic review. Int J Behav Nutr Phys Act, 5, 56. doi: 10.1186/1479-5868-5-56.

Samayoa, L., Grace, S.L., Gravely, S., Scott, L.B., Marzolini, S., \& Colella, T.J. (2014). Sex differences in cardiac rehabilitation enrollment: A meta-analysis. Can J Cardiol, 30(7), 793-800. doi: 10.1016/j.cjca.2013.11.007

Sanderson, B.K., Mirza, S., Fry, R., Allison, J.J., \& Bittner, V. (2007). Secondary prevention outcomes among black and white cardiac rehabilitation patients. Am Heart J, 153(6), 980-6.

Sarrafzadegan, N., Rabiei, K., Kabir, A., Sadeghi, M., Khosravi, A., Asgari, S., ...Roohafza, H. (2008). Gender differences in risk factors and outcomes after cardiac rehabilitation. Acta Cardiol,63(6), 763-70. 
Scott, L.A., Ben-Or, K., Allen, J.K. (2002). Why are women missing from outpatient cardiac rehabilitation programs? A review of multilevel factors affecting referral, enrollment, and completion. J Womens Health (Larchmt),11(9):773-91.

Smith, S.C., Allen, J., Blair, S.N., Bonow, R.O., Brass, L.M., Fonarow, G.C., .. Taubert, K.A. (2006). AHA/ACC guidelines for secondary prevention for patients with coronary and other atherosclerotic vascular disease: 2006 update. Circulation, 113(19), 2363-72. Retrieved from http://circ.ahajournals.org/content/113/19/2363.long

Smith, S.C., Benjamin, E.J., Bonow, R.O., Braun, L., Creager, M., Franklin,... Taubert, K. (2011). AHA/ACCF Secondary Prevention and Risk Reduction Therapy for Patients with Coronary and other Atherosclerotic Vascular Disease: 2011 update: A guideline from the American Heart Association and American College of Cardiology Foundation.

Circulation, 124(22), 2458-73. doi: 10.1161/CIR.0b013e318235eb4d

Stauffer, M.E., Weisenfluh, L., \& Morrison, A. (2013). Association between triglycerides and cardiovascular events in primary populations: A meta-regression analysis and synthesis of evidence. Vasc Health Risk Manag, 9, 671-680. doi: 10.2147/VHRM.S52713

The PEACE Trial Investigators. (2004) Angiotensin-Converting-Enzyme Inhibition in stable coronary artery disease. $N$ Engl J Med, 351(20), 2058-2068.

Thomas RJ, King M, Lui K, Oldridge N, Piña IL, Spertus J, ... Whitman, G.R. (2007). AACVPR/ACC/AHA 2007 Performance measures on cardiac rehabilitation for referral to and delivery of cardiac rehabilitation/secondary prevention services. J Am Coll Cardiol, 50(14),1400-33. Retrieved from http://www.sciencedirect.com/science/article/pii/ S0735109707013393 
Vaccarino, V., Krumholz, H.M., Yarzebski, J., Gore, J.M., \& Goldberg, R.J. (2001). Sex differences in 2-year mortality after hospital discharge for myocardial infarction. Ann Intern Med,134(3),173-181.

Vogel, D., Franklin, B., Salmon, R., Reid, K., Saxon, W., Faircloth, G., ... Gordon, N. (2005). Multi-center study of risk factor status on completion of a contemporary phase 2 cardiac rehabilitation program: male versus female patients. [Abstract], J Cardiopulm Rehabil, $25,304$.

Wen, C.P., Wai, J.P.M., Tsai, M.K., Yang, Y.C., Cheng, T.Y.D., Lee, M-C., ... Wu., X. (2011). Minimum amount of physical activity for reduced mortality and extended life expectancy: a prospective cohort study. The Lancet, 378(9798), 1244-1253.

West, R.R., Jones, D.A., \& Henderson, A.H. (2012). Rehabilitation after myocardial infarction trial (RAMIT): Multi-centre randomised controlled trial of comprehensive cardiac rehabilitation in patients following acute myocardial infarction. Heart, 98(8), 637-644. doi: 10.1136/heartjnl-2011-300302

Wisconsin Cardiac Rehabilitation Outcomes Registry. (2014). WiCORE. Available: https:// wicore.wisc.edu/About.aspx. Accessed December 12, 2014.

Wisconsin Society for Cardiovascular and Pulmonary Health and Rehabilitation (WISCPHR). WiCORE Data dictionary. Milwaukee, Wisconsin: WISCPHR, 2008.

Yancy, C.W., Jessup, M., Bozkurt, B., Butler, J., Casey, D. E., Drazner, M.H., ...Wilkoff, B.L. (2013). 2013 ACCF/AHA Guideline for the management of heartâ failure: A report of the American College of Cardiology Foundation/American Heart Association Task Force on Practice Guidelines. J Am Coll Cardiol, 62(16), e147-e239. 
Table 1. AHA/ACC secondary prevention goals

\begin{tabular}{ll}
\hline Factor & Goal \\
\hline Total cholesterol & $<200 \mathrm{mg} / \mathrm{dl}$ \\
Low-density lipoprotein & $<100 \mathrm{mg} / \mathrm{dl}$ \\
High-density lipoprotein & $>40 \mathrm{mg} / \mathrm{dl}$ \\
Triglycerides & $<150 \mathrm{mg} / \mathrm{dl}$ \\
\hline Body mass index & $18.5-24.9\left(\mathrm{~kg} / \mathrm{m}^{2}\right)$ \\
\hline Systolic blood pressure & $<140 \mathrm{~mm} / \mathrm{Hg}$ \\
\hline Diastolic blood pressure & $<90 \mathrm{~mm} / \mathrm{Hg}$ \\
\hline Systolic blood pressure (patient has & $<130 \mathrm{~mm} / \mathrm{Hg}$ \\
diabetes or chronic kidney disease) & \\
\hline $\begin{array}{l}\text { Diastolic blood pressure (patient has } \\
\text { diabetes or chronic kidney disease) }\end{array}$ & $<80 \mathrm{~mm} / \mathrm{Hg}$ \\
\hline HbA ${ }_{1 C}$ (patient has diabetes) & $<7 \%$, \\
Physical activity & $\geq 150 \mathrm{~min} / \mathrm{week}$ \\
Smoking cessation & Complete cessation \\
\hline Medication (if no contra-indication) & \\
B-Blocker & Compliance \\
ACE-I/ARB & Compliance \\
\hline Aspirin & Compliance \\
\hline Lipid-lowering & Compliance \\
\hline
\end{tabular}

(Source: Smith et al., 2006; American Association of Cardiovascular and Pulmonary Rehabilitation, 2013). 
Table 2. Pre-CR sociodemographic and clinical characteristics of enrolled patients by CR completion

\begin{tabular}{|c|c|c|c|}
\hline Characteristic & $\begin{array}{c}\text { Enrollees Only } \\
(\mathrm{n}=4,047,31.2 \%)\end{array}$ & $\begin{array}{l}\text { CR Completers } \\
(\mathrm{n}=8,929,68.8 \%)\end{array}$ & $\bar{p}$ \\
\hline $\begin{array}{l}\text { Ethnic background (\% } \\
\text { white) }\end{array}$ & 91.2 & 96.0 & $\begin{array}{c}.001 \\
\end{array}$ \\
\hline Age (years, mean \pm SD) & $63.1 \pm 12.7$ & $65.7 \pm 11.4$ & $<.001$ \\
\hline \multicolumn{4}{|l|}{ AACVPR risk $\uparrow(\%)$} \\
\hline Low & 29.0 & 35.0 & $<.001$ \\
\hline Moderate & 38.2 & 37.7 & 0.645 \\
\hline High & 32.8 & 27.3 & $<.001$ \\
\hline \multicolumn{4}{|l|}{ CR indication (\%) } \\
\hline PCI & 54.0 & 47.8 & $<.001$ \\
\hline MI & 32.3 & 30.5 & 0.097 \\
\hline CABG & 26.4 & 35.0 & $<.001$ \\
\hline VR & 10.0 & 12.5 & 0.001 \\
\hline Angina & 7.5 & 6.1 & 0.014 \\
\hline $\mathbf{H F}$ & 4.5 & 3.2 & 0.001 \\
\hline Prev CHD & 34.7 & 30.8 & $<.001$ \\
\hline \multicolumn{4}{|l|}{ Comorbidities (\%) } \\
\hline Diabetes & 33.6 & 28.2 & $<.001$ \\
\hline Arthritis & 30.8 & 28.5 & 0.021 \\
\hline GI disease & 18.5 & 17.3 & 0.151 \\
\hline Pulmonary Disease & 14.5 & 11.5 & $<.001$ \\
\hline Depression & 23.0 & 12.9 & $<.001$ \\
\hline Back pain & 13.8 & 9.4 & $<.001$ \\
\hline
\end{tabular}




\begin{tabular}{lccc}
\hline Cancer & 7.4 & 7.6 & 0.791 \\
PV Disease & 9.0 & 6.9 & 0.001 \\
Renal disease & 8.8 & 6.8 & 0.001 \\
Stroke & 6.4 & 6.2 & 0.708 \\
Mental health & 11.1 & 6.0 & $<.001$ \\
condition & & & \\
MS condition & 6.2 & 5.4 & 0.113 \\
Chronic pain & 6.3 & 4.3 & $<.001$ \\
Smoking status $(\%)$ & & & $<.001$ \\
Never & 33.3 & 43.4 & 0.287 \\
Former & 40.8 & 42.0 & $<.001$ \\
Current & 25.9 & 14.6 &
\end{tabular}

†Source: American Association of Cardiovascular and Pulmonary Rehabilitation, 2004.

Abbreviations: CR, cardiac rehabilitation; PCI, percutaneous coronary intervention; CABG, coronary artery bypass graft surgery; MI, myocardial infarction; VR, valve repair/ replacement; HF, heart failure; Prev CHD, previous history of coronary heart disease; GI, gastrointestinal; PV, peripheral vascular; MS, musculoskeletal. 
Table 3. Pre-CR sociodemographic and clinical characteristics of the patients that completed $\mathbf{C R}$, and by gender

\begin{tabular}{|c|c|c|c|}
\hline Characteristic & $\begin{array}{c}\text { Women } \\
(n=2,695,30.2 \%)\end{array}$ & $\begin{array}{c}\text { Men } \\
(n=6,234,69.8 \%)\end{array}$ & $\mathbf{p}^{*}$ \\
\hline $\begin{array}{l}\text { Ethnic background (\% } \\
\text { white) }\end{array}$ & 95.3 & 96.5 & 0.079 \\
\hline Age (years, mean \pm SD) & $67.7 \pm 11.6$ & $64.8 \pm 11.1$ & $<.001$ \\
\hline \multicolumn{4}{|l|}{ AACVPR risk $\uparrow(\%)$} \\
\hline Low & 33.7 & 35.5 & 0.073 \\
\hline Moderate & 38.0 & 37.6 & 0.196 \\
\hline High & 28.3 & 26.9 & 0.129 \\
\hline \multicolumn{4}{|l|}{ CR indication (\%) } \\
\hline PCI & 47.6 & 46.6 & 0.401 \\
\hline CABG & 28.6 & 37.7 & $<.001$ \\
\hline $\mathbf{V R}$ & 15.3 & 11.2 & $<.001$ \\
\hline Angina & 3.4 & 2.7 & 0.102 \\
\hline MI & 6.7 & 4.8 & 0.917 \\
\hline HF & 4.0 & 2.8 & $<.001$ \\
\hline Prev CHD & 26.4 & 32.4 & $<.001$ \\
\hline \multicolumn{4}{|l|}{ Comorbidities (\%) } \\
\hline Diabetes & 29.3 & 27.8 & 0.166 \\
\hline Arthritis & 34.2 & 26.0 & $<.001$ \\
\hline GI disease & 19.6 & 16.3 & $<.001$ \\
\hline Pulmonary Disease & 12.7 & 11.0 & 0.064 \\
\hline Depression & 15.6 & 9.3 & $<.001$ \\
\hline Back pain & 9.9 & 9.2 & 0.302 \\
\hline
\end{tabular}




\begin{tabular}{lccc}
\hline Cancer & 7.8 & 7.5 & 0.601 \\
PV Disease & 6.7 & 7.1 & 0.556 \\
Renal disease & 7.6 & 6.4 & $<.05$ \\
Stroke & 6.8 & 6.0 & 0.166 \\
Mental health & 7.8 & 5.2 & $<.001$ \\
condition & & & 0.208 \\
MS condition & 6.2 & 5.0 & $<.001$ \\
Chronic pain & 6.0 & 3.5 & \\
Smoking status $(\%)$ & & & $<.001$ \\
Never & 56.7 & 37.7 & $<.001$ \\
Former & 31.5 & 46.5 & $<.001$ \\
Current & 11.8 & 15.8 & \\
\hline
\end{tabular}

*Comparisons between men and women. †Source: American Association of Cardiovascular and Pulmonary Rehabilitation, 2004.

Abbreviations: CR, cardiac rehabilitation; PCI, percutaneous coronary intervention; CABG, coronary artery bypass graft surgery; MI, myocardial infarction; VR, valve repair/ replacement; HF, heart failure; Prev CHD, previous history of coronary heart disease; GI, gastrointestinal; PV, peripheral vascular; MS, musculoskeletal. 
Table 4. Changes in secondary prevention measures in women and men from pre to post-cardiac rehabilitation

\begin{tabular}{|c|c|c|c|c|c|c|c|}
\hline \multirow[b]{2}{*}{ Measure } & \multicolumn{2}{|c|}{ Women $(\mathrm{n}=\mathbf{2 , 6 9 5 )}$} & \multicolumn{2}{|c|}{$\operatorname{Men}(n=6,234)$} & \multicolumn{2}{|c|}{ Change in measure } & \multirow[b]{2}{*}{ CID in literature } \\
\hline & Pre & Post & Pre & Post & Women & Men & \\
\hline BMI $\left(\mathrm{kg} / \mathrm{m}^{2}\right)$ & $30.3 \pm 7.1$ & $29.9 \pm 7.1$ & $30.0 \pm 5.7$ & $29.7 \pm 5.6$ & $-0.4 \pm 5.0$ & $-0.3 \pm 5.1$ & \\
\hline WC (inch) & $38.6 \pm 6.6$ & $37.8 \pm 6.4$ & $41.7 \pm 5.6$ & $41.0 \pm 5.4$ & $-0.8 \pm 3.4$ & $-0.7 \pm 2.5$ & \\
\hline $\mathrm{TC}(\mathrm{mg} / \mathrm{dl})$ & $179.6 \pm 45.9$ & $162.9 \pm 38.8^{*}$ & $165.5 \pm 45.0$ & $148.4 \pm 39.3^{*}$ & $-16.7 \pm 39.3$ & $-17.1 \pm 37.4$ & $\begin{array}{l}-10 \% \text { of baseline TC } \\
\text { (Gould et al., 1998) }\end{array}$ \\
\hline $\mathrm{TG}(\mathrm{mg} / \mathrm{dl})$ & $147.7 \pm 90.7$ & $140.5 \pm 80.8^{*}$ & $148.7 \pm 112.0$ & $131.0 \pm 93.0^{*}$ & $-7.2 \pm 59.1$ & $-16.7 \pm 79.2^{\S}$ & \\
\hline $\operatorname{LDL}(\mathrm{mg} / \mathrm{dl})$ & $102.7 \pm 40.0$ & $87.2 \pm 33.7^{*}$ & $97.2 \pm 38.3$ & $83.0 \pm 33.0^{*}$ & $-15.5 \pm 33.6$ & $-14.2 \pm 31.4$ & $\begin{array}{l}-10 \mathrm{mg} / \mathrm{dl} \text { (Briel et al. } \\
2009)\end{array}$ \\
\hline $\operatorname{HDL}(\mathrm{mg} / \mathrm{dl})$ & $48.7 \pm 21.5$ & $48.5 \pm 19.5$ & $39.9 \pm 11.6$ & $40.4 \pm 13.5$ & $-0.2 \pm 22.2$ & $0.42 \pm 11.3$ & \\
\hline SYS (mmHg) & $121.1 \pm 17.4$ & $119.5 \pm 15.0^{*}$ & $119.1 \pm 17.0$ & $119.0 \pm 15.0$ & $-1.6 \pm 17.8$ & $-0.1 \pm 17.4^{\S}$ & \\
\hline DIA (mmHg) & $68.0 \pm 15.0$ & $67.0 \pm 9.0 *$ & $68.2 \pm 10.1$ & $67.7 \pm 14.8 *$ & $-1.1 \pm 17.7$ & $-0.5 \pm 15.8$ & \\
\hline $\mathrm{HbA}_{1 \mathrm{C}}(\%) \dagger$ & $7.3 \pm 1.5$ & $7.0 \pm 1.1^{*}$ & $7.2 \pm 1.6$ & $6.8 \pm 1.4^{*}$ & $-0.3 \pm 1.2$ & $-0.4 \pm 1.2$ & \\
\hline Physical activity & $42.0 \pm 85$ & $161.0 \pm 92^{*}$ & $62.0 \pm 102$ & $193.0 \pm 117^{*}$ & $119.0 \pm 105$ & $130.0 \pm 131^{\S}$ & 15 minutes/day (Wen \\
\hline
\end{tabular}


(min/week)

Current tobacco

smoking (\%)

Medications

B-blockers $(\%)$

ACE-I/ARB (\%)

64.2

97.9

97.9

94.3

Lipid-lowering (\%)

93.8 et al., 2011)

Quitting (Critchley \&

Capewell, 2003)

95.6

95.0

0.2

$-0.5$

Values are expressed as mean value \pm standard deviation.

${ }^{*} \mathrm{p}<.05$ for significant change in scores from pre to post-CR within-gender; ${ }^{\varsigma} \mathrm{p}<.05$ for significant gender difference in change scores from pre- to post-CR.

†among $\mathrm{n}=2,522$ patients diagnosed with diabetes.

Abbreviations: CID, Clinically-important difference; BMI, body mass index; WC, waist circumference; TC, total cholesterol; TG, triglycerides; LDL, low-density lipoprotein; HDL, high-density lipoprotein; SYS, systolic blood pressure; DIA, diastolic blood pressure; $\mathrm{HbA}_{1 \mathrm{C}}$, Hemoglobin A1c; ACE-I, angiotensin converting enzyme-inhibitors/ ARB, Angiotensin II receptor blocker. 
Table 5. Proportion of patients at AHA/ACC secondary prevention goals pre- and post-CR and by gender, and the change in proportion at AHA/ACC secondary prevention goals

\begin{tabular}{|c|c|c|c|c|c|c|c|c|c|}
\hline \multirow{3}{*}{ AHA/ACC goals } & \multicolumn{3}{|c|}{ Overall $(\mathrm{N}=8,929)$} & \multicolumn{3}{|c|}{ Women $(n=2,695)$} & \multicolumn{3}{|c|}{ Men $(n=6,234)$} \\
\hline & $\%$ Pre & $\%$ Post & Change & $\%$ Pre & $\%$ Post & Change & $\%$ Pre & $\%$ Post & Change \\
\hline & & & $\%$ & & & $\%$ & & & $\%$ \\
\hline $\mathrm{TC}<200 \mathrm{mg} / \mathrm{dl}$ & 76.6 & 87.7 & $11.1 *$ & 70.3 & 83.7 & $13.40 *$ & 81.1 & 89.3 & $8.2 *$ \\
\hline $\mathrm{LDL}<100 \mathrm{mg} / \mathrm{dl}$ & 56.0 & 74.4 & $18.4 *$ & 52.7 & 72.6 & $19.90 *$ & 58.9 & 75.6 & $16.7 *$ \\
\hline $\mathrm{HDL}>40 \mathrm{mg} / \mathrm{dl}$ & 49.2 & 50.2 & 1.0 & 68.7 & 67.9 & -0.80 & 41.5 & 42.5 & 1.0 \\
\hline $\mathrm{TG}<150 \mathrm{mg} / \mathrm{dl}$ & 63.7 & 70.7 & $7.0 *$ & 62.0 & 65.2 & $3.20 *$ & 65.9 & 73.0 & $7.1 *$ \\
\hline BMI $18.5-24.9 \mathrm{~kg} / \mathrm{m}^{2}$ & 16.9 & 17.6 & 0.7 & 21.1 & 22.2 & 1.10 & 15.0 & 15.6 & 0.6 \\
\hline WC: $\mathrm{W}<35$ inch & NA & NA & NA & 28.2 & 31.8 & $3.6^{*}$ & NA & NA & NA \\
\hline $\mathrm{M}<40$ inch & NA & NA & NA & NA & NA & NA & 37.3 & 43.1 & $5.8^{*}$ \\
\hline $\mathrm{SYS}<140 \mathrm{~mm} / \mathrm{Hg} \dagger$ & 87.5 & 91.4 & $3.9 *$ & 84.5 & 91.0 & $6.50 *$ & 88.8 & 91.5 & $2.7 *$ \\
\hline $\mathrm{DIA}<90 \mathrm{~mm} / \mathrm{Hg} \dagger$ & 97.6 & 98.4 & 0.8 & 98.0 & 99.0 & 1.00 & 97.4 & 98.1 & 0.7 \\
\hline $\mathrm{SYS}<130 \mathrm{~mm} / \mathrm{Hg} \ddagger$ & 70.2 & 72.8 & $2.6 *$ & 67.2 & 72.2 & $5.00 *$ & 71.5 & 73.1 & $1.6 *$ \\
\hline
\end{tabular}




\begin{tabular}{|c|c|c|c|c|c|c|c|c|c|}
\hline $\mathrm{DIA}<80 \mathrm{~mm} / \mathrm{Hg} \ddagger$ & 85.0 & 87.9 & $2.9 *$ & 86.4 & 89.8 & $3.40 *$ & 84.3 & 87.1 & $2.8 *$ \\
\hline $\mathrm{HbA}_{1 \mathrm{C}}<7 \%$, diabetes & 50.4 & 60.7 & $10.3 *$ & 48.6 & 54.8 & $6.20 *$ & 51.1 & 63.6 & $12.5 *$ \\
\hline Physical activity & 15.3 & 66.1 & $50.8 *$ & 10.6 & 57.7 & $47.10 *$ & 17.1 & 69.7 & $52.6 *$ \\
\hline \multicolumn{10}{|l|}{$(\geq 150 \mathrm{~min} /$ week $)$} \\
\hline Smoking § & 85.5 & 93.8 & $8.3 *$ & 88.2 & 94.2 & $6.00 *$ & 84.2 & 93.6 & $9.4 *$ \\
\hline \multicolumn{10}{|l|}{ Medication } \\
\hline B-blocker & 94.6 & 94.2 & -0.4 & 92.2 & 92.4 & 0.20 & 95.5 & 95.0 & -0.5 \\
\hline ACE-I/ARB & 64.8 & 64.0 & -0.8 & 64.2 & 63.5 & -0.70 & 65.0 & 64.3 & -0.7 \\
\hline Aspirin & 98.1 & 98.1 & 0.0 & 97.9 & 97.9 & 0.00 & 98.2 & 98.2 & 0.0 \\
\hline Lipid-lowering & 95.1 & 95.3 & 0.2 & 93.8 & 94.3 & 0.50 & 95.6 & 95.7 & 0.1 \\
\hline
\end{tabular}

$* \mathrm{p}<.05$

$\uparrow$ No diabetes or renal disease; $\$$ For patients with diabetes or renal disease. $\S$ Never and former smokers.

Abbreviations: AHA/ACC, American Heart Association and the American College of Cardiology; CR, cardiac rehabilitation; BMI, body mass index; WC, waist circumference; W, women; M, men; NA, not applicable; TC, total cholesterol; TG, triglycerides; LDL, low-density lipoprotein; HDL, high-density lipoprotein; SYS, systolic blood pressure; DIA, diastolic blood pressure; HbA 1 ,

Hemoglobin A1c for diabetic patients; ACE-I, angiotensin converting enzyme- inhibitors/ ARB, Angiotensin II receptor blocker. 
Table 6. Adjusted odds ratios (AOR) for women versus men not at target pre-program achieving AHA/ACC secondary prevention goals post-CR using generalized estimating equations models

\begin{tabular}{|c|c|c|c|c|c|}
\hline \multirow[t]{2}{*}{ Dependent Variable* } & \multirow[t]{2}{*}{$\mathbf{N} \dagger$} & \multirow[t]{2}{*}{ AOR } & \multicolumn{2}{|c|}{$95 \% \mathrm{CI}$} & \multirow[t]{2}{*}{$\mathbf{p}$} \\
\hline & & & Lower & Upper & \\
\hline $\mathrm{TC}<200 \mathrm{mg} / \mathrm{dl}$ & 720 & 0.83 & 0.62 & 1.12 & 0.22 \\
\hline $\mathrm{LDL}<100 \mathrm{mg} / \mathrm{dl}$ & 1395 & 0.91 & 0.75 & 1.11 & 0.37 \\
\hline $\mathrm{HDL}>40 \mathrm{mg} / \mathrm{dl}$ & 2234 & 1.39 & 1.05 & 1.86 & 0.023 \\
\hline $\mathrm{TG}<150 \mathrm{mg} / \mathrm{dl}$ & 1548 & 0.54 & 0.45 & 0.66 & $<0.001$ \\
\hline BMI 18.5-24.9 & 7323 & 1.21 & 0.96 & 1.54 & 0.11 \\
\hline $\mathrm{SYS}<140 \mathrm{~mm} / \mathrm{Hg} t$ & 734 & 0.99 & 0.71 & 1.38 & 0.94 \\
\hline $\mathrm{DIA}<90 \mathrm{~mm} / \mathrm{Hg} \dagger$ & 140 & 0.61 & 0.22 & 1.71 & 0.35 \\
\hline $\mathrm{SYS}<130 \mathrm{~mm} / \mathrm{Hg} \S$ & 682 & 1.19 & 0.77 & 1.84 & 0.44 \\
\hline DIA $<80 \mathrm{~mm} / \mathrm{Hg} \S$ & 419 & 0.94 & 0.60 & 1.48 & 0.80 \\
\hline $\mathrm{HbA}_{1 \mathrm{C}}<7 \%$, diabetic patient & 379 & $\mathbf{0 . 5 0}$ & 0.32 & 0.78 & 0.002 \\
\hline Physical activity ( $\geq 150 \mathrm{~min} /$ week) & 5834 & 0.66 & 0.59 & 0.74 & $<0.001$ \\
\hline Smoking cessation\| & 1200 & 0.88 & 0.68 & 1.13 & 0.31 \\
\hline \multicolumn{6}{|l|}{ Medication } \\
\hline ß-Blocker & 205 & .88 & 0.40 & 1.95 & 0.76 \\
\hline ACE-I/ARB & 1972 & 1.17 & 0.91 & 1.51 & 0.23 \\
\hline Aspirin & 206 & 1.14 & 0.86 & 1.51 & 0.38 \\
\hline Lipid-lowering & 328 & 0.92 & 0.82 & 1.03 & 0.13 \\
\hline
\end{tabular}

$*$ Male is the reference category for each of the listed variables. $\uparrow$ Excluding patients at target pre-program 
Each model controlled for the set of variables listed in Statistical Analyses section.

† No diabetes or renal disease; $§$ For patients with diabetes or renal disease. || Never and former smokers.

Abbreviations: AHA/ACC, American Heart Association and the American College of Cardiology; LDL, low-density lipoprotein; TC, total cholesterol; HDL, high-density lipoprotein; TG, triglycerides; BMI, body mass index; SYS, systolic blood pressure; DIA, diastolic blood pressure; ACE-I, angiotensin converting enzyme-inhibitors/ARB, Angiotensin II receptor blocker; CI, confidence interval. 


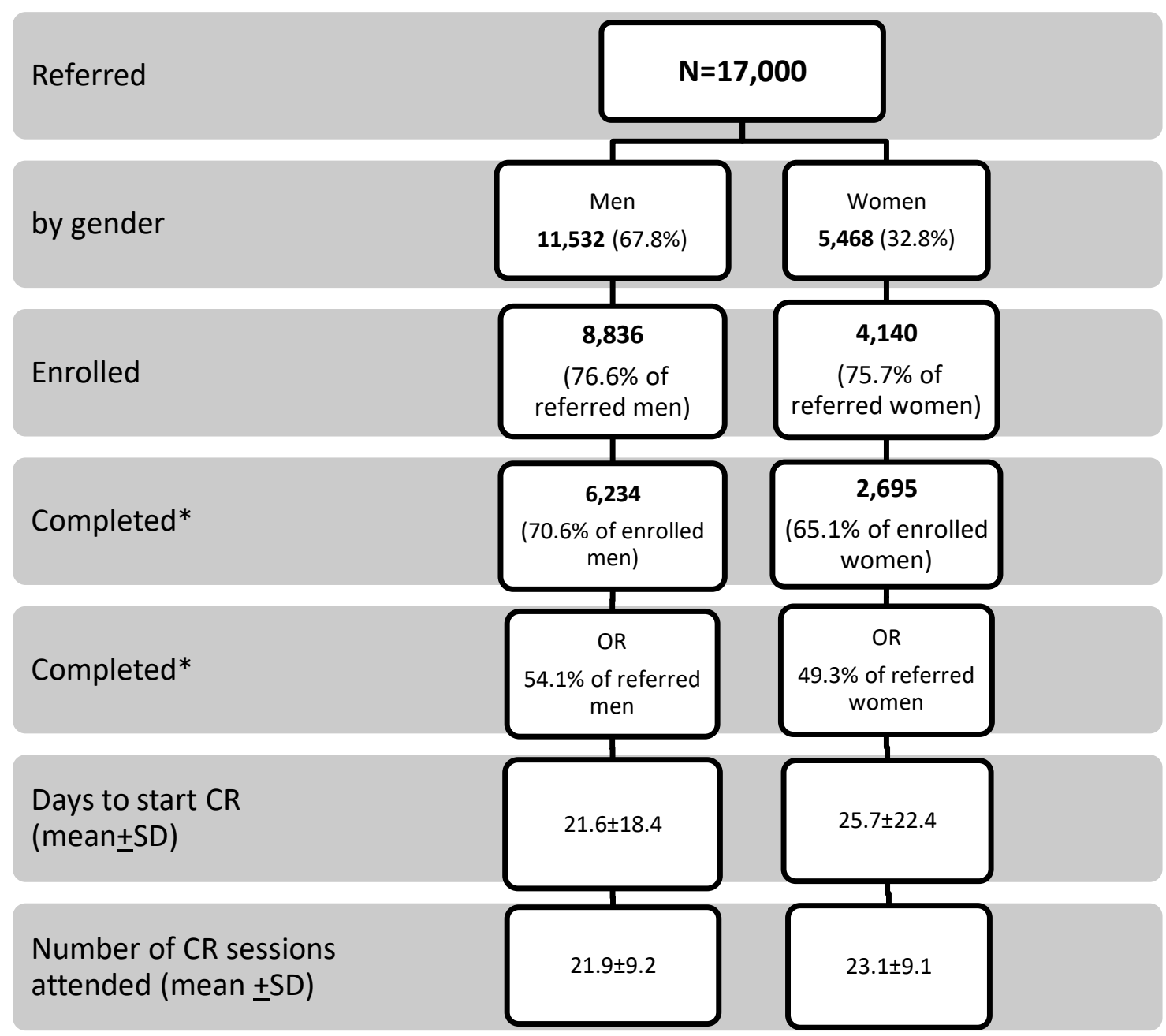

Figure 1: Cardiac rehabilitation utilization by gender in the Wisconsin registry.

*significant difference between men and women $(\mathrm{p}<.05)$

$\mathrm{CR}=$ cardiac rehabilitation; $\mathrm{SD}=$ standard deviation. 


\section{Appendix}

\section{Operationalization of the AHA/ACC Secondary Prevention Goals in the WiCORE data dictionary}

\begin{tabular}{|ll|} 
Outcome & Measurement \\
Blood Pressure & Measured directly by CR staff as follow: \\
& - Measure seated resting blood pressure on $\geq 2$ visits prior to exercise at \\
program entry and once prior to exercise at program discharge. & - Measure blood pressure in both arms \\
\hline Lipids & Measures are obtained from patient medical records : \\
& - Record at program entry and discharge the most recent fasting \\
& measures of total cholesterol, high-density lipoprotein, low-density \\
& lipoprotein, and triglycerides. \\
& - Assess current treatment and compliance.
\end{tabular}

Each outcome is assessed at entry and discharge of the cardiac rehabilitation program. 